\title{
Perancangan Marketplace Investasi Peternakan Online pada Startup Farmerid
}

\author{
Meme Susilowati , Hadi Nur Wahid
}

\begin{abstract}
FarmerID is a platform in the field of farms that bring together farmers with investors. The obstacle that FarmerID answers today is that transactions are manually recorded, and there is no online media. So FarmerID takes a long time to make a decision whether or not it is necessary to manually check the static number of livestock, the speed of the system is still less efficient. Related to that, farmers still can not ensure that the media can be accessed and accessed by the public to know about farmers. This Information System works as follows, to help FarmerID conduct online transactions in order to make transactions whenever, wherever, by anyone, to view information and information about what to do, as well as to learn about the processes and business processes of FarmerID.
\end{abstract}

Index Terms-Livestock investment marketplace, livestock, investment, laravel, php.

\begin{abstract}
Abstrak--FarmerID merupakan platform dibidang peternakan yang mempertemukan antara peternak dengan investor. Kendala yang dihadapi FarmerID saat ini adalah pencatatan transaksi dilakukan secara manual, serta tidak adanya media pemasaran secara online. Sehingga FarmerID membutuhkan waktu yang lama untuk membuat keputusan apakah investasi diterima atau ditolak karena harus mengecek secara manual jumlah ketersediaan stok ternak, tentunya sistem ini masih kurang efisien. Dalam segi pemasaran FarmerID juga belum maksimal karena tidak ada media yang dapat diketahui dan diakses oleh masyarakat luas untuk mencari tahu tentang FarmerID. Sistem Informasi ini memiliki fungsi sebagai berikut, untuk membantu FarmerID melakukan transaksi secara online agar dapat melakukan transaksi kapanpun, dimanapun, oleh siapa pun, untuk memantau ketersediaan ternak dan kondisi ternak tanpa harus berada di lokasi peternakan, juga untuk memasarkan kepada masyarakat tentang profil dan proses bisnis FarmerID.
\end{abstract}

Kata Kunci-Marketplace investasi peternakan, peternakan, investasi, laravel, php.

\section{INTRODUCTION}

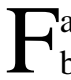
armerID merupakan sebuah startup bisnis yang bergerak dalam bidang peternakan. FarmerID merupakan platform yang mempertemukan antara peternak yang memiliki lahan dan kemampuan untuk mengelola peternakan dengan pemilik modal / investor

Meme Susilowati adalah dosen Program Studi Sistem Informasi Universitas Machung (email : meme.susilowati@machung.ac..id)

Hadi Nur Wahid adalah mahasiswa Program Studi Sistem Informasi Universitas Machung (e-mail: 321410004@student.machung.ac.id) yang memiliki dana dan ingin menjalankan usaha dalam bidang peternakan tetapi tidak memiliki kemampuan dan pengetahuan untuk mengelola peternakan dengan baik, dan disinilah FarmerID menjalanankan perannya sebagai perantara kedua belah pihak. Komoditas ternak yang ada pada FarmerID adalah ternak besar sapi dan kambing dan tidak menutup kemungkinan untuk memperluas komoditas lainnya. FarmerID menawarkan berbagai kemudahan bagi calon investor untuk dapat menginvestasikan dananya pada bidang peternakan, di FarmerID sudah tersedia beberapa partner peternakan terpercaya yang siap bekerjasama dan menampung serta mengelola ternak milik investor. Dengan FarmerID para investor juga tidak perlu khawatir dengan kondisi kesehatan ternaknya, karena FarmerID akan memantau dan memastikan keadaan ternak dengan baik secara berkala dan melaporkannya kepada investor. Jika dilihat dari pihak peternak, FarmerID juga turut serta membantu mendorong tingkat ekonomi dan kesejahteraan para peternak karena para pertenak akan mendapatkan bagi hasil yang adil dari hasil penjualan ternak yang dikelolanya.

Proses bisnis yang ditawarkan oleh FarmerID yakni investor dapat memilih terlebih dahulu jenis komoditi yang ingin diternak dengan pertimbangan investor akan melihat informasi berupa jenis ternak, harga investasi, pilihan jangka waktu investasi dan perkiraan return investasi yang akan di dapat. Setelah investor menentukan hewan ternaknya dan membayar harga investasi ke pihak FarmerID, lalu FarmerID akan mengikimkan hewan ternak tersebut ke petenak untuk dirawat oleh peternak dalam jangka waktu tertentu yang telah ditentukan oleh pihak investor dan FarmerID, pada saat masa investasi telah selesai dan tiba saat panen FarmerID akan menawarkan pilihan kepada investor apakah investor ingin memperpanjang jangka investasi atau ingin langsung menarik bagi hasil atas investasi ternaknya. Jangka waktu investasi pada FarmerID terbagi dalam waktu 3bulan, 6bulan, dan 1 tahun. Jangka waktu ini termasuk kedalam investasi jangka pendek yang merupakan salah satu keunggulan utama proses bisnis yang ditawarkan oleh FarmerID, sehingga investor tidak perlu menunggu waktu yang lama untuk memperoleh hasil investasinya.

Dengan segala keunggulan dan kemudahan yang ditawarkan membuat FarmerID yakin dapat memperoleh target pasar yang sangat luas dan dapat bekerjasama dengan berbagai vendor yang dapat menunjang kelancaran operasional FarmerID. FarmerID memiliki peluang untuk terus berkembang untuk 
memperbesar lingkup bisnisnya, mengingat banyaknya kebutuhan daging nasional bagi masyarakat Indonesia khususya daging sapi, kambing, ayam dan ikan yang belum tercukupi. Kendala yang dihadapi FarmerID saat ini adalah segala transaksi dan kegiatan operasional yang dilakukan oleh FarmerID masih dilakukan secara manual, tidak adanya aplikasi maupun Sistem Informasi yang dapat membatu melakukan pencatatan transaksi secara tersistem dan juga untuk melakukan transaksi dan sekaligus promosi secara online.

Hingga saat ini proses pencatatan transaksi dan penerimaan transaksi pada FarmerID masih dilakukan secara manual, sehingga membutuhkan waktu yang cukup lama untuk dapat membuat keputusan apakah investasi dari masyarakat dapat diterima atau ditolak karena harus mengecek secara manual jumlah ketersediaan stok ternak, tentunya sistem ini masih kurang efisien. Oleh karena hal tersebut, FarmerID memerlukan sebuah Sistem Informasi Marketplace yang dapat membantu FarmerID untuk menangani segala proses bisnis yang dijalankan FarmerID.

Sistem Informasi ini akan dirancang dengan basis online agar dapat dilakukan transaksi kapanpun, dimanapun, dan oleh siapa pun. Selain itu manajemen FarmerID juga dapat memantau transaksi yang terjadi, ketersediaan ternak, dan kondisi ternak dengan mudah tanpa harus berada di lokasi peternakan. Sistem ini diharapkan dapat mempermudah dan menyingkat waktu transaksi yang sebelumnya dilakukan secara manual, sehingga transaksi dapat terjadi dengan lebih mudah dan efisien. Selain itu sistem informasi ini dapat digunakan oleh divisi marketing dapat melakukan input data komoditas ternak yang tersedia untuk menerima investasi dan msyarakat yang tertarik untuk berinvestasi juga dapat melihat komoditas ternak yang dapat investasikan. Sistem ini juga berfungsi sebagai pencatat transaksi investasi yang terjadi setiap saat dan akan secara otomatis memastikan ketersediaan stok ternak yang tersedia, mendapatkan dan menarik perhatian dari entitas yang ingin bekerjasama dengan FarmerID seperti peternak dan mitra pihak ketiga untuk penjualan hasil ternak yang siap panen seperti pabrik olahan daging. Sistem ini akan sangat membantu FarmerID karena membuat proses penjualan lebih cepat dan efisien.

Sistem Informasi Marketplace yang akan dirancang untuk FarmerID ini berfungsi untuk memasarkan kepada masyarakat umum tentang profil dan proses bisnis FarmerID sendiri. Marketplace ini harus dirancang sebaik dan sedetail mungkin agar masyarakat dapat dengan mudah mengetahui dan memahami proses bisnis dari FarmerID, pada marketplace ini akan disajikan informasi berupa profil perusahaan, latar belakang perusahaan, komoditi ternak yang tersedia serta informasi mengenai simulasi bagi hasil sehingga dengan sistem ini pihak investor dapat melihat hasil perkiraan pendapatan bagi hasil setiap periodenya. Dengan sistem informasi tersebut diharapkan akan dapat menarik minat dari masyarakat untuk berinvestasi melalui FarmerID.

\section{TINJAUAN PUSTAKA}

Penelitian yang dilakukan oleh Elizaandaya Ginting seorang mahasiswi Sistem Informasi angkatan Universitas Widyatama Bandung yang berjudul "Aplikasi Penjualan Berbasis Web (E-Commerce) Menggunakan JOOMLA Pada Mutiara Fashion(2013)" bertujuan untuk membantu Mutiara Fashion dalam mempromosikan dan menjual produk kepada konsumen. Selain itu tujuan lain adalah memberikan kemudahan dalam pengolahan data transaksi serta pembuatan laporan [1].

Penelitian lain yang diambil berjudul "Pembuatan $E$ commerce Pada Distro Java Trend" oleh Sri Peni dan Bambang Eka bertujuan untuk membangun sebuah aplikasi penjualan berbasis e-commerce, dimana pelanggan dapat melakukan pembelian, pembayaran, dan pengiriman barang secara online pada website dan dapat membantu Distro Java Trend dalam meningkatkan sarana promosi yang baik serta dapat meningkatkan penjualan Distro Java Trend. [2].

Sistem informasi adalah suatu sistem didalam suatu organisasi yang mempertemukan kebutuhan pengelolaan transaksi harian, mendukung operasi, bersifat manajerial, dan kegiatan strategi dari suatu organisasi dan menyediakan pihak luar tertentu dengan laporan-laporan yang dibutuhkan [3].

Pengertian dari online marketplace adalah segala usaha yang dilakukan untuk melakukan pemasaran suatu produk atau jasa melalui atau menggunakan media Internet atau jaringan www, sedangkan place sendiri dalam kamus bahasa inggris artinya adalah tempat. Disini dapat disimpulkan pengertian dari Online Market Place adalah tempat atau wadah untuk melakukan pemasaran produk atau jasa melalui atau menggunakan media Internet [4].

Investasi dapat diartikan sebagai komitmen untuk menanamkan sejumlah dana pada saat ini dengan tujuan memperoleh keuntungan di masa datang. Dengan kata lain, investasi merupakan komitmen untuk mengorbankan konsumsi sekarang dengan tujuan memperbesar konsumsi di masa dating [5].

Peternakan merupakan kegiatan budidaya dan mengembangbiakkan hewan ternak untuk diambil manfaat dan hasil dari ternak tersebut. Lingkup peternakan tidak terbatas pada memelihara ternak saja, karena memelihara dan peternakan sangat berbeda, perbedaannya terletak pada tujuan yang ingin dicapainya. Tujuan peternakan adalah memperoleh keuntungan dari menjalankan peternakan dengan standar operasional yang telah ditetapkan. Peternakan dapat mencakup hampir semua jenis komoditi, tetapi peternakan dapat dibedakan atas dua golongan yakni peternakan hewan besar seperti sapi, kerbau dan kuda, sedangkan golongan kedua yakni peternakan hewan kecil seperti ayam, kelinci dan lain sebagainya [6].

Three Major Phases merupakan tiga tahap utama yang bertujuan merencanakan dan mengontrol proyek yang akan dibangun agar berhasil dilaksanakan. Ketiga tahap utama tersebut adalah analisis, desain dan implementasi. Pada tahap analisis, kegiatan yang dilakukan adalah mengumpulkan data, alur data dan analisis keputusan, dan persiapan prososal. Pada tahap 
desain, kegiatan yang dilakukan adalah mendesain data inputan yang diperlukan, desain input dan output dan pengaturan data. Sedangkan pada tahap implementasi dibagi menjadi dua kegiatan yaitu implementasi dan evaluasi [7].

\section{Metode PENELITIAN}

Metode penelitian yang digunakan adalah metode pengembangan sistem dengan menggunakan Three Major Phases yang terdiri dari tiga langkah utama yaitu analisis, desain, dan implementasi, akan tetapi pada jurnal ini hanya dibahas tahap analisis dan desain sistem.

1) Analisis, yang terdiri dari:

a. Pengumpulan data (data gathering).

Pada tahap data gathering aktifitas yang dilakukan adalah pengumpulan data yang diperlukan untuk pengembangan sistem dengan menggunakan metode pengamatan atau observasi yang dilakukan tempat usaha peternakan milik startup farmerid yang terletak di desa Pujo Kidul, kabupaten Malang. Pada proses pengamatan ini telah didapatkan data yang berupa proses bisnis mulai dari pembelian bibit ternak hingga penjualan hasil panen ternak, sehingga data yang didapat adalah data yang tepat sehingga dapat digunakan untuk pengembangan sistem pada tahap desain. Dari hasil pengamatan ini didapatkan sebuah grand design sistem informasi untuk startup Framerid yangempat modul yaitu modul marketing, modul manufaktur dan modul keuangan.

b. Analisis keputusan dan arus data (data flow and decision analysis)

Berdasarkan analisis permasalah yang ada, maka diperoleh desain workflow marketplace (Gambar 1), dengan penjelasan sebagai berikut:

- FarmerID melakukan pembelian bibit siap ternak kepada peternak apabila bibit tersedia maka akan terjadi transaksi pembelian bibit kepada peternak. Hasil dari pembelian bibit diinputkan kedalam katalog website FarmerID

- Investor melakukan pencarian komoditas atau bibit ternak pada website FarmerID, setelah ada yang diinginkan maka investor melakukan pembayaran sesuai dengan harga dan jumlah ternak yang akan diinvestasikan.

- Setelah itu FarmerID akan melakukan konfirmasi kepada peternak untuk dilakukan proses pemeliharaan ternak

- Setelah periode tertentu ternak akan masuk kedalam daftar siap panen dan dapat diakses melalui katalog pembelian hasil panen.

- Pembeli melakukan pencarian hasil

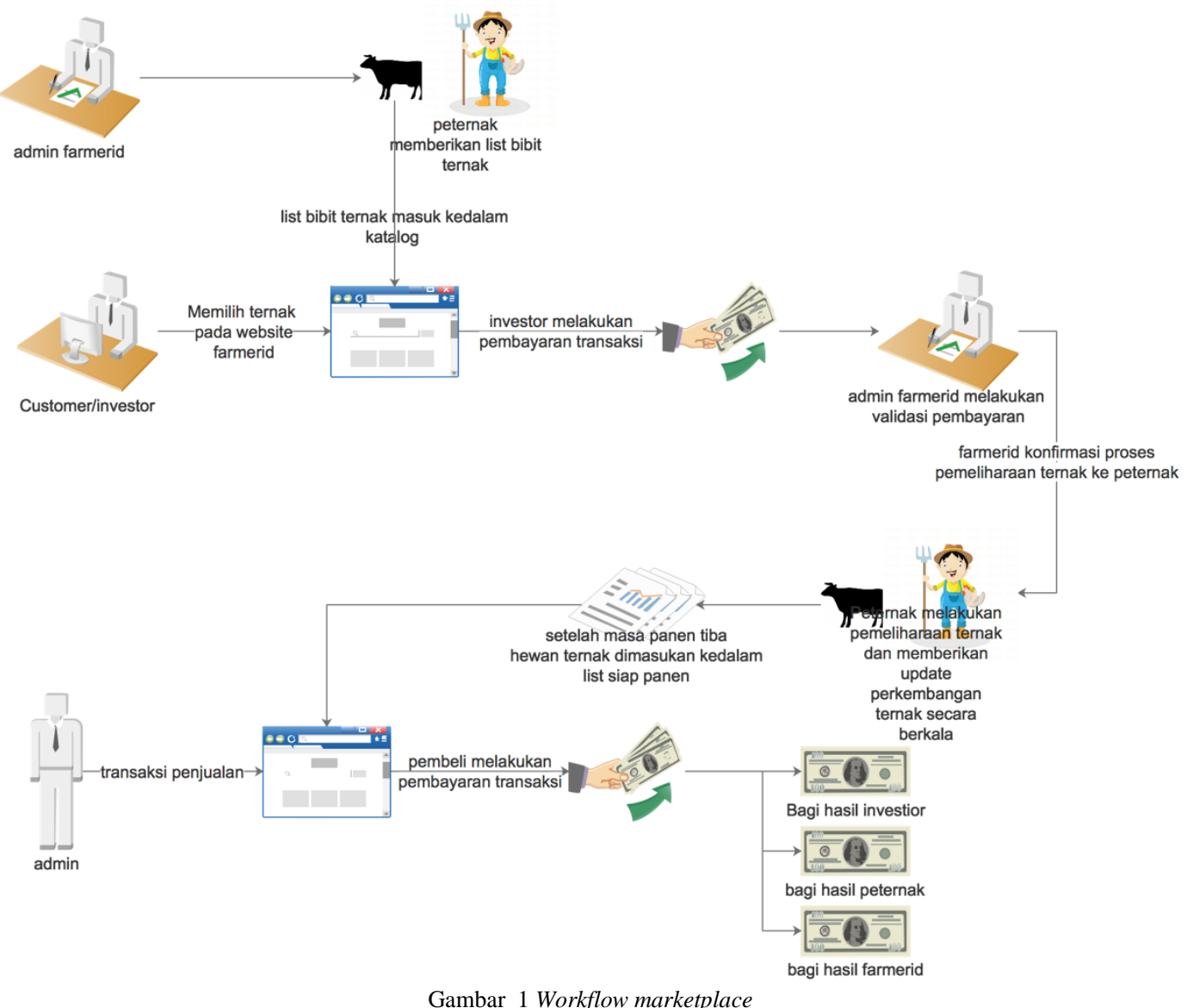

Gambar 1 Workflow marketplace 
Tabel 1 Kebutuhan Informasi Pengguna

\begin{tabular}{|c|c|c|c|}
\hline No & Pengguna & Hak Akses & Kebutuhan \\
\hline 1 & $\begin{array}{l}\text { Admin } \\
\text { FarmerID }\end{array}$ & $\begin{array}{ll}\text { 1. } & \text { Melakukan pembelian bibi } \\
\text { ternak } \\
\text { 2. Melakukan approval transaksi } \\
\text { investasi } \\
\text { 3. Melakukan approval transaksi } \\
\text { hasil panen } \\
\text { 4. Melakukan approval penarikan } \\
\text { dana oleh peternak dan } \\
\text { investor } \\
\text { 5. Melakukan approval registrasi } \\
\text { peternak } \\
\text { 6. Melihat seluruh riwayat } \\
\text { transaksi } \\
\text { 7. Melihat seluruh komoditas } \\
\text { ternak }\end{array}$ & $\begin{array}{l}\text { Data master komoditas, jenis komoditas, data } \\
\text { customer, data peternak dan data prosentase } \\
\text { bagi hasil. }\end{array}$ \\
\hline 2 & Peternak & $\begin{array}{l}\text { 1. Melakukan update kondisi } \\
\text { ternak secara berkala } \\
\text { 2. Melakukan penarikan saldo } \\
\text { bagi hasil }\end{array}$ & $\begin{array}{l}\text { Data jenis komoditas ternak, data master } \\
\text { komoditas dan data transaksi investasi. }\end{array}$ \\
\hline 3 & Investor & $\begin{array}{l}\text { 1. Melakukan registrasi } \\
\text { 2. Melakukan transaksi investasi } \\
\text { 3. Melakukan penarikan saldi } \\
\text { bagi hasil }\end{array}$ & $\begin{array}{l}\text { Data peternak, data master komoditas, dana } \\
\text { prosentase bagi hasil }\end{array}$ \\
\hline 4 & Pembeli & $\begin{array}{l}\text { 1. Melakukan registrasi } \\
\text { 2. Melakukan transaksi } \\
\text { pembelian hasil panen ternak }\end{array}$ & Data ternak siap panen. \\
\hline
\end{tabular}

panen ternak pada katalog web, setelah menemukan ternak yang diinginkan pembeli melakukan pembayaran. Dari hasil pembayaran ini akan dilakukan bagi hasil keuntungan kepada investor, peternak dan FarmerID.

c. Kebutuhan Fungsional

Pada tahap ini juga telah dilakukan perancangan kebutuhan fungsional sistem sebagai berikut:

- Sistem dapat mencatat dan mengolah dan menampilkan data master

- Sistem dapat mencatat dan mengolah data transaksi pembelian bibit.

- Sistem dapat mencatat dan mengolah data transaksi investasi.

- Sistem dapat mencatat dan mengolah data transaksi hasil panen.

- Sistem dapat mencatat dan mengolah data transaksi bagi hasil.

Tahap ini juga membahas kebutuhan informasi pengguna (Tabel 1).

2) Desain, yang terdiri dari:

a. Desain data entri (data entry design).

Pada tahap ini terdiri dari perancangan use case diagram, activity diagram dan sitemap. Use case yang digunakan dalam perancangan sistem adalah sebagai berikut:

- Use case marketplace investasi menggambarkan seluruh proses bisnis yang terjadi pada bisnis investasi

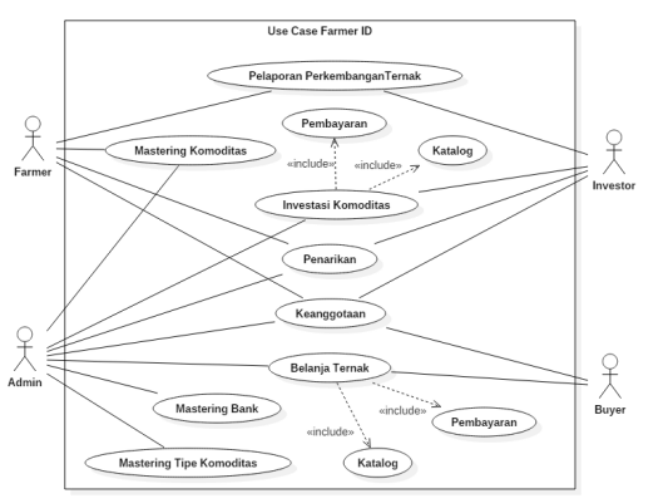

Gambar 2 Use case marketplace peternakan secara online dapat dilihat pada (Gambar 2).

- Diagram aktivitas yang terdapat pada sistem marketplace ini adalah :

Diagram aktivitas registrasi investor Gambar 3) untuk yang dilakukan ketika seorang customer atau investor yang ingin memiliki akun di farmerid. Aktifitas yang dilakukan adalah customer melakukan registasi dengan cara klik registrasi setelah itu maka sistem akan menampilkan form yang berisi nama, email dan password. Email yang digunakan harus bersifat unik karena satu email hanya bias digunakan untuk satu kali saja. Setelah diisikan sistem akan melakukan pengecekan redundansi data apabila ada data yang sudah ada maka sistem akan 


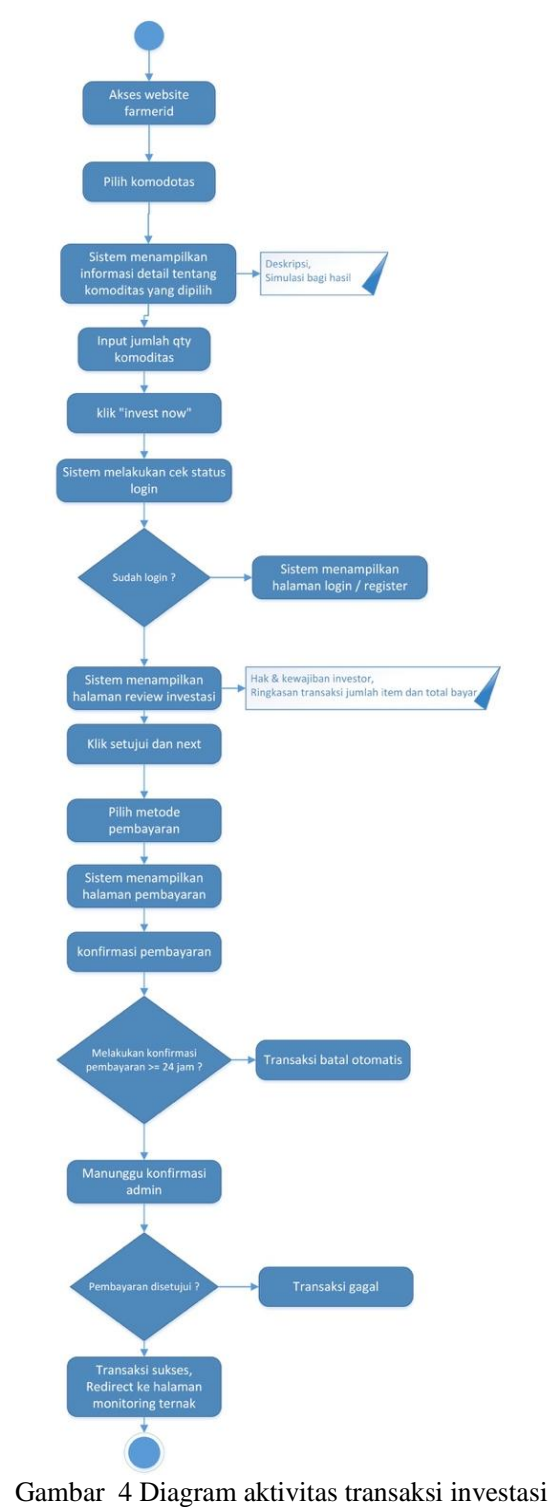

memberikan notifikasi kepada customer jika sudah ada data yang sama yang telah digunakan. Setelah berhasil melakukan registrasi dengan menggunakan email maka selanjutnya adalah mengisi data pribadi yang berupa nama lengkap, tanggal lahir, sumber dana, alamat dan lain-lain.

- Diagram transaksi investasi (Gambar 4).

Aktifitas yang dilakukan adalah investor adalah membuka website farmerid kemudian mencari pada komoditas katalog, kemudian mengisikan jumlah investasi dan melakukan konfirmasi pembayaran, setelah melakukan konfirmasi pembayaran data transaksi ternak akan tersimpan kedalam database dan investor dapat mengakses data riwayat transaksi.

- Diagram aktivitas transaksi penjualan hasil panen oleh pembeli (Gambar 5). Sistem menampilkan daftar ternak yang siap panen, kemudian administrator

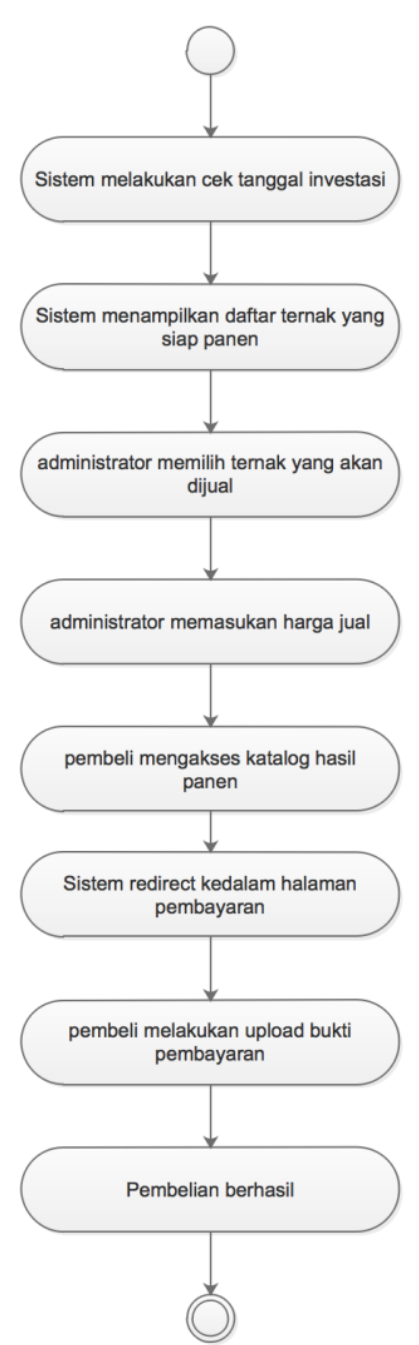

Gambar 5 Diagram aktivitas penjualan hasil panen

memilih ternak yang siap panen dan memasukkan harga jual panen maka ternak siap panen akan masuk kedalam katalog hasil panen. Setelah itu pembeli dapat mengakses website penjualan hasil panen dan masuk kedalam katalog kemudian memilih ternaknya, pembeli melakukan klik tombol beli dan masuk kedalam halaman pembayaran setelah itu pembeli melakukan upload bukti pembayaran.

Sitemap sistem admin (Gambar 6) dan sitemap front-end (Gambar 7) dibagi dalam delapan menu. Administrator dapat mengakses menu sebagai berikut:

- Dashboard yang berisi grafik seluruh transaksi.

- Menu mastering yang digunakan untuk melakukan mastering data

- Menu pembelian bibit, penjualan panen dan menu approval

Sedangkan pengguna bagian depan atau front-end user terdiri dari peternak, investor dan pembeli hasil panen.

b. Diagram $E-R$ berupa perancangan struktur database sistem marketplace investasi peternakan dapat dilihat pada (Gambar 8). 

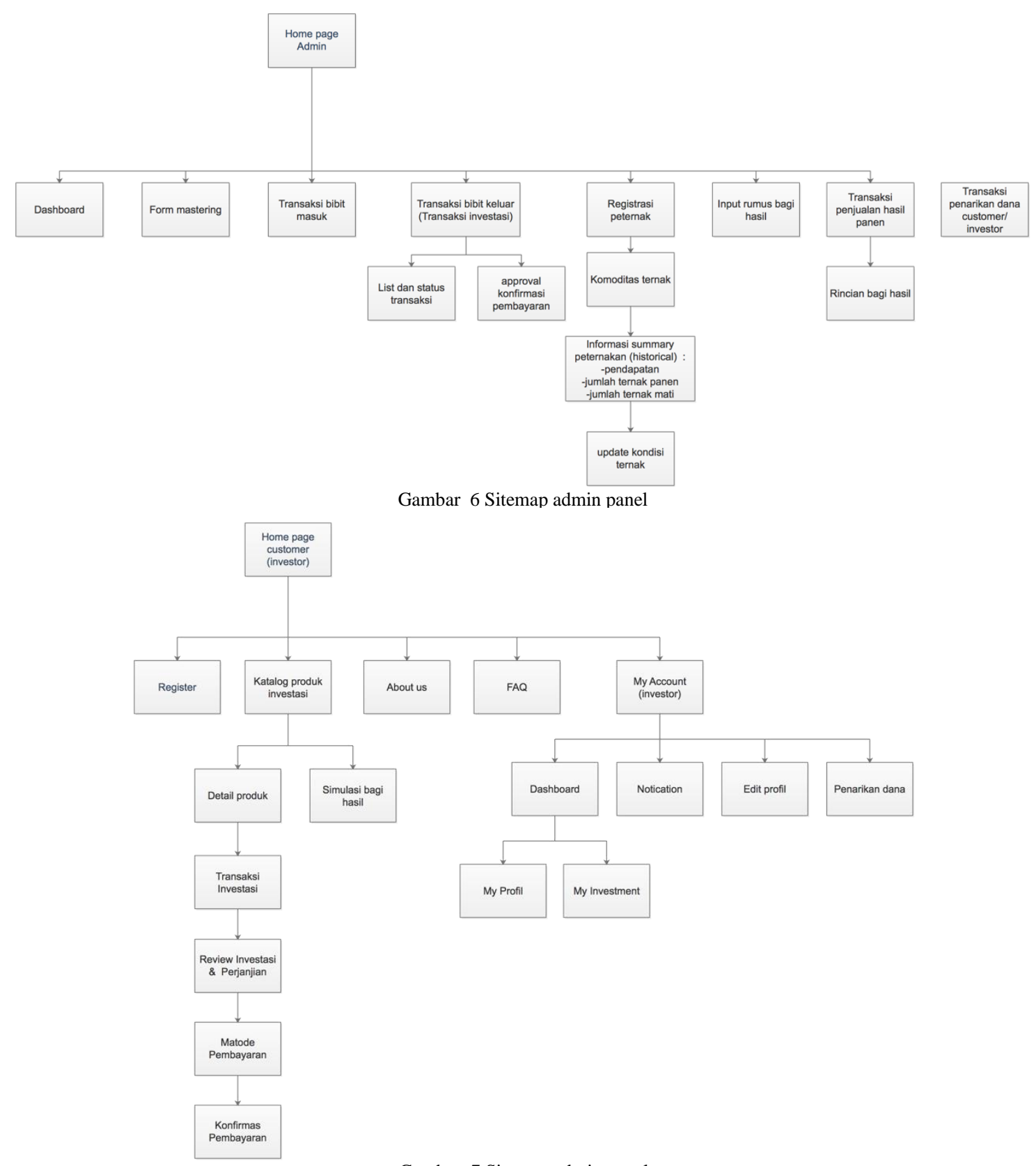

Gambar 7 Sitemap admin panel

\section{HASILDAN PEMBAHASAN}

Berdasarkan rancangan yang telah dibuat, maka dikembangkanlah sebuah sistem marketplace investasi peternakan online pada untuk stratup FarmerID yang terdiri dari empat actor yaitu peternak, investor, pembeli panen dan administrator. Setiap actor memiliki tampilan dan hak akses yang berbeda. Seperti pada peternak dapat melakukan usulan komoditas ternak dan dapat memberikan deskripsi, harga yang hanya dapat diubah oleh peternak sehingga aktor lain tidak dapat melakukan penyalahgunaan hak akses.

\section{KESIMPULAN DAN SARAN}

Sistem Marketplace investasi peternakan online dengan studi kasus startup farmerID ini dibangun dengan bahasa pemrograman PHP dan framework laravel dan menggunakan database MariaDB dengan menerapkan metode pengembangan sistem Three Major
Phase. Sistem marketplace investasi ini dikembangkan sesuai dengan kebutuhan proses bisnis startup FarmerID, sistem ini dapat melakukan :

1) Menjadi company profile untuk startup farmerid.

2) Mencatat registrasi farmer, investor dan buyer.

3) Mencatat transaksi pembelian bibit komoditas.

4) Mencatat transaksi pembelian komoditas hasil panen.

5) Mencatat riwayat setiap transaksi yang telah terjadi

Saran pengembangan untuk sistem informasi akuntansi pada penyedia jasa laundry adalah sebagai berikut:

1) Sistem dikembangkan agar ketika terjadi transaksi masing-masing actor bisa mendapatkan email notification.

2) Sistem dikembangkan dengan menambahkan fitur back order atau wihslist komoditas yang telah habis stok. 


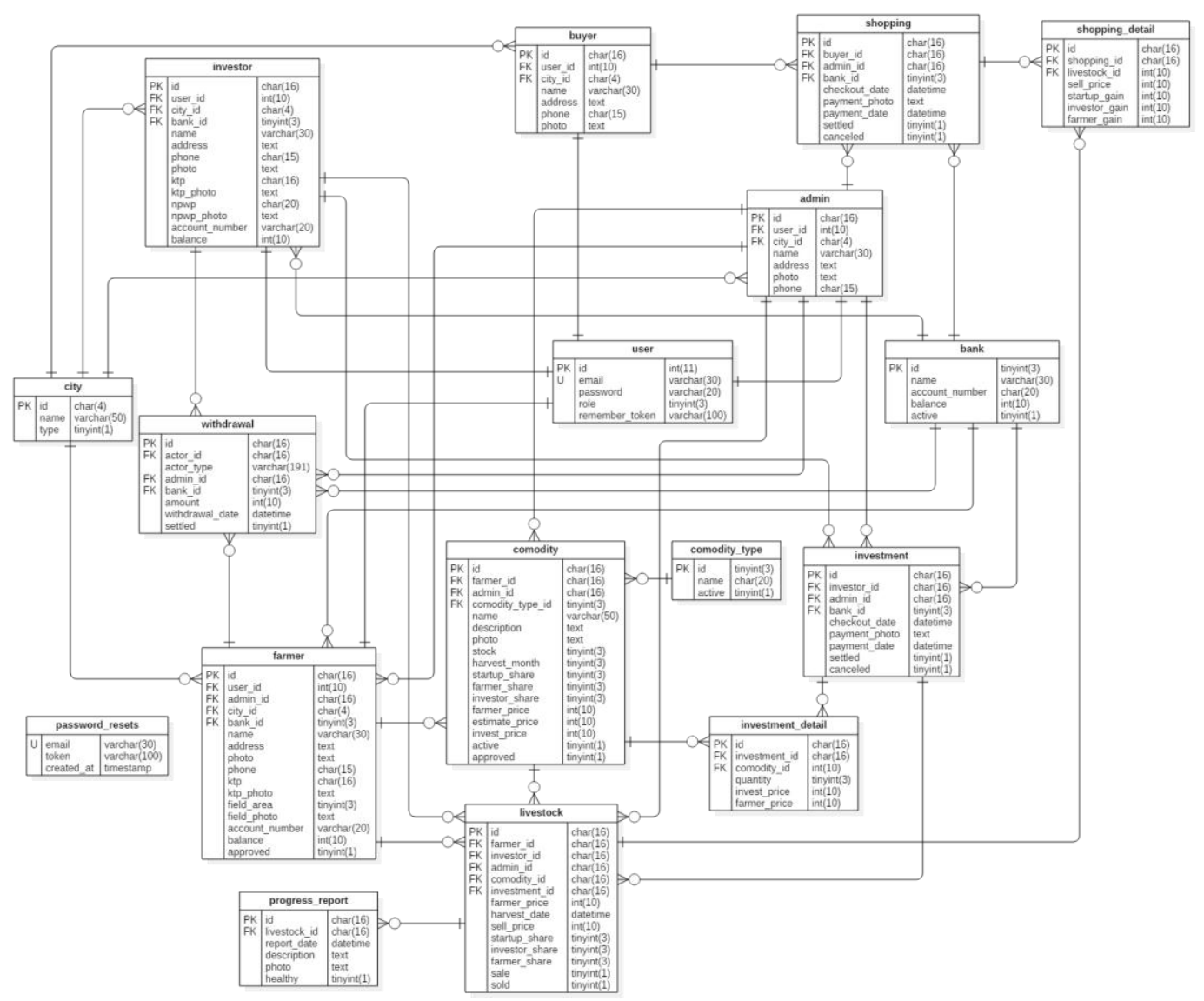

Gambar 8 Diagram E-R marketplace investasi peternakan online

3) Sistem dikembangkan lebih lanjut dengan menambahkan sistem informasi manajemen dan supply chain management untuk mempermudah rantai pasok komoditas.

\section{DAFTAR PUSTAKA}

[1] Ginting, Elizaandayni. (2013). Aplikasi Penjualan Berbasis Web (E-Commerce) Menggunakan Joomla Pada Mutiara Fashion. Widyatama Repository.

[2] Handayani dan Purnama. (2013). Pembuatan Website ECommerce Pada Distro Java Trend. Seminar Riset Unggulan Nasional Informatika dan Komputer FTI UNSA 2013.

[3] Dewi Anggadini, S. (2013). Analisis Sistem Informasi Manajemen Berbasis Komputer dalam Proses Pengambilan Keputusan. Volume. ISSN 1411-9374.

[4] Saputra, S. d. (2013). Perancangan Online Marketplace Untuk Usaha Kecil dan Menengah (Ukm) Di Kabupaten Purworejo. Jurnal Ilmiah DASI, 14, 54-58.

[5] PSAK. (2015). Standar Akuntansi Keuangan. PSAK 13 Properti Investasi.

[6] Weriza, Jusmita. 2016. Sistem Informasi Berbasis Web pada Dinas Peternakan dan Perikanan Kabupaten Tanah Datar. UPI YPTK Jurnal KomTekInfo Vol. 3, No.

[7] Kendall, J.E. and Kendall, K.E., 2013, Systems Analysis and Design, 9e ed, Pretince Hall, United States. 